\title{
O marketing profissional e suas interfaces: a valorização do bibliotecário em questão
}

\section{Nádia Elôina Barcelos Fraga}

Professora do Departamento de Ciências da Informação, Universidade Federal do Espírito Santo (convênio Faculdade de Farmácia e Bioquímica do Espírito Santo); Especialista em Documentação e Informação, IBICT; Especialista em Educação a Distância para Formação de Orientadores Acadêmicos, UFES/UFMT

Carla Erler Mattos

\section{Graduada em Biblioteconomia pela Universidade Federal do Espírito Santo- UFES}

Gabriela de Almeida Cassa

Graduada em Biblioteconomia pela Universidade Federal do Espírito SantoUFES

Apresenta o marketing profissional, apropriando-se de concepções clássicas do marketing, do endomarketing e do marketing pessoal, descritas na literatura da área de Biblioteconomia e de Administração. Em face da emergência de ações que visem o reconhecimento e a valorização social do bibliotecário, propõe-se destacar estereótipos construídos em torno de sua imagem, que ofuscam uma correta visibilidade pública da profissão. Descreve ações voltadas para a aplicação do marketing à promoção desta imagem em nível pessoal, acadêmico e institucional. Considera ser necessário o investimento conjunto na divulgação profissional, por parte de instituições formadoras e dos órgãos representativos da classe, a fim de consolidar uma imagem positiva do bibliotecário.

Palavras-chave: Marketing profissional; Bibliotecário; Valorização profissional; Estereótipos. 


\title{
Professional marketing and its interfaces: valuation of the librarian questioned
}

\begin{abstract}
Professional marketing is discussed, using classic conceptions of marketing, endomarketing and personal marketing, described in the literature in the areas of Administration and Library Sciences. Because of the emergent need in actions that aim at the compensation and social valuation of the librarian, the article suggests to distinguish stereotypes made around his/her image, which hinder a correct public visibility of the profession. It also describes actions for application of marketing for image promotion in personal, academic and institutional levels, especially by education institutions and representative category associations in order to consolidate a positive image of the librarian.
\end{abstract}

Keywords:Professional marketing. ;Librarian. Professional; valuation; Stereotypes.

Recebido em 28.04.2008 Aceito em 18.06.2008

\section{Introdução}

A prática bibliotecária sempre esteve fincada na organização, preservação e guarda do acervo, focada num modelo de formação tecnicista e operacional. Mudanças significativas vêm ocorrendo, no contexto mundial, refletindo a necessidade de se reexaminar o conjunto de competências e habilidades inerentes ao perfil desejável do bibliotecário, em prol dessas mudanças e de sua valorização profissional.

O fenômeno conhecido por explosão bibliográfica, assim caracterizado em meados do século $X X$, criou a emergência do uso do computador em bibliotecas, com o objetivo de auxiliar o bibliotecário nos processos de organização e tratamento da informação, para fins de disponibilização e recuperação (CAMPELLO; CENDON; KREMER, 2000). Desde então, a Biblioteconomia encontra-se quase sempre desafiada diante dos avanços da tecnologia.

$\mathrm{Na}$ década de 90, a área se depara com um novo compromisso: deslocar o foco do paradigma centrado no acervo, para o paradigma centrado na informação. Sob as lentes deste paradigma, o bibliotecário volta-se mais expressivamente para as necessidades do usuário do que para a preocupação excessiva em organizar acervos (OLIVEIRA, 1996). 
Frente a essa realidade imposta em dimensão global, até onde sabemos, a profissão pode ter ganhado maior importância social, mas não o reconhecimento almejado nessa mesma proporção. Provavelmente, porque a sua imagem continua envolvida em estereótipos que ofuscam uma correta visibilidade pública dessa profissão. Segundo Souto (2005), vários fatores antecedem essa situação. Considera a questão cultural como sendo uma das variáveis limitantes à sua aceitação e reconhecimento social, entre outras, inerentes ao processo formativo em passado recente, geralmente direcionando a atuação mais para a dimensão técnica do que para as atividades gerenciais.

Felizmente, essa situação está mudando. Embora não reconheça de forma definitiva o valor do bibliotecário, a sociedade evidencia a todo instante a carência de um profissional conhecedor das técnicas de organização da informação, que disponha de conhecimentos gerenciais/administrativos e domine as tecnologias da informação (SOUTO, 2005, p. 30).

Apesar disso, mediante observações feitas empiricamente no cotidiano profissional do bibliotecário, percebe-se a falta de atitude do mesmo em benefício da sua imagem. Deve, o próprio bibliotecário, investir na divulgação de sua profissão, desde o seu ingresso no curso, a fim de mostrar à sociedade quem é e o que faz. Tais investimentos podem reverter o sentido desta revelação feita há dez anos e, ao que tudo indica, ainda procede:

A divulgação da profissão de bibliotecário tem sido relegada, ao longo da história da Biblioteconomia brasileira. O registro de experiências no desenvolvimento de estratégias e metodologias para divulgação é pouco na literatura da área (EGGERT; MARTINS, 1996, p. 45).

Sob este prisma, um dos aspectos que mais se sobressai no escopo de tal temática sugere indagações como esta a que se propõe responder: Quais ações ligadas ao marketing podem ser implementadas pela classe bibliotecária para prover melhorias à sua visibilidade pública, a fim de se obter o reconhecimento e valorização profissional perante a sociedade?

Portanto, este artigo aborda aspectos ligados à valorização do bibliotecário, cuja escolha temática justifica-se por sua relevância técnicocientífica em face do número reduzido de contribuições registradas na literatura (EGGERT; MARTINS, 1996) que ressaltem, especialmente, interfaces do marketing profissional com o endomarketing e o marketing pessoal, como possibilidades de se proverem melhorias à imagem do bibliotecário. Deve-se considerar, também, a existência de lacunas no âmbito da produção discente do Departamento de Ciências da Informação do CCJE/UFES. Até o momento, o assunto não foi tratado sob a ótica que se propõe tratar aqui. Contudo, KUPLICH (2004), nas conclusões de seu estudo, atenta para a possibilidade de se "[...] investir no Marketing 
Profissional para que a Biblioteconomia brasileira alcance uma visibilidade social compatível com a sua verdadeira função social [...]".

Visando-se essa valorização, a relevância deste artigo, no entendimento das autoras, está em apresentar o marketing profissional mediante a apropriação de concepções clássicas do marketing, do endomarketing e do marketing pessoal. Entende-se que não seria adequado fazer uma mera transposição dessas abordagens para um contexto distinto, embora ligado; ou seja, marketing profissional. Por isso, se fez necessário abordar vários níveis de aprendizado para a construção do objeto de estudo, tais como: - Destacar os estereótipos construídos em torno da imagem do bibliotecário; Reconhecer concepções clássicas do marketing, do endomarketing e do marketing pessoal; e Descrever ações voltadas para a aplicação do marketing à promoção da imagem do bibliotecário.

Firma-se, assim, a intenção de propor a aplicação de estratégias do marketing profissional, elaboradas a partir do endomarketing e do marketing pessoal, nas ações cotidianas do bibliotecário, como possibilidade de obtenção do seu reconhecimento e valorização social.

Visando atingir os objetivos informados, realizou-se um estudo monográfico, com base em registros coletados da bibliografia concernente à área de Biblioteconomia e Administração, destacando-se que os procedimentos metodológicos adotados nesta construção fundamentam-se nas fases da pesquisa bibliográfica, formalizadas em obras de autores tais como Gil (1995); Lakatos e Marconi (1992); Severino (2000), dentre outros estudiosos no assunto. As fontes selecionadas referem-se a contribuições mais expressivas em conteúdos afins ao desenvolvimento da temática que envolve interfaces do marketing profissional com o endomarketing e com o marketing pessoal, dentre outros aspectos. As referências compiladas na última seção cobrem registros fornecidos no período de 1990 a 2005, com exceção das contribuições fornecidas por MC Carthy (1976) e Simões (1978). Estas fontes foram utilizadas para situar historicamente o marketing.

\section{Os estereótipos construídos em torno da imagem do bibliotecário}

Há milênios, o homem percebeu a necessidade de preservar a quantidade de conhecimento gerado e acumulado ao longo de sua existência. Tornou-se impossível armazenar em sua memória todo o saber gerado em determinada época, e registrado em suportes que evoluíram da pedra e argila ao papiro e pergaminho, até o surgimento do papel no século XV. Mais recentemente, o hipertexto passou a representar "[...] o último capítulo da história da escrita e do livro, o livro interativo, audiovisual, multimídia" (PARENTE, 1999 citado por SILVA; TOMAÉL, 2004, p. 7). A figura da pessoa encarregada de zelar e organizar acervos surgiu na Antiguidade, com a criação das primeiras bibliotecas particulares e monásticas, de acesso restrito a uma pequena parcela da população que dominava os códigos da escrita (MILANESI, 2002). 
O responsável pelas bibliotecas desde a Antiguidade até o início do Renascimento, "[...] menos se caracterizou como um organizador que existia para facilitar as incursões dos curiosos pelo universo do conhecimento e mais se afirmou como um devotado e estranho guardião do saber $[. . .]^{\prime \prime}$ (MILANESI, 2002, p. 16).

Como se pode perceber, a prática bibliotecária remonta a várias épocas. No entanto, no Brasil, o primeiro curso de Biblioteconomia foi oferecido pela Biblioteca Nacional, em 1911, sendo que a profissão só veio a ser regulamentada com a Lei nº. 4. 084, de 30 de junho de 1962 (TARGINO, 2006).

Esta profissão vem evoluindo muito ao longo dos anos, em especial nas últimas décadas, influenciada pelas mudanças ocorridas no contexto mundial, tais como: a explosão documental, os avanços da tecnologia, a mudança de paradigma e as exigências cada vez maiores detectadas no mundo do trabalho (GUIMARÃES, 2004). Tudo isto implica a reformulação do perfil desse profissional, buscando desenvolver competências e habilidades inerentes à sua atuação em contextos diferenciados da Biblioteconomia.

Embora sejam inegáveis esses avanços, a profissão parece não ter alcançado o status pretendido. A imagem do bibliotecário continua associada àquela de guardião do acervo, em conformidade com o que observou Milanesi (2002). A própria formação do bibliotecário, baseada no paradigma acervo num passado recente, pode ter contribuído para a construção desse estereótipo. Isso porque, até a década de 80 , 0 bibliotecário contava com uma formação altamente tecnicista, em que, levada à prática, concorria para maiores preocupações centradas na organização, guarda e preservação do acervo; características estas muito salientes no seu perfil atual.

Tal como afirma Pinto e Barrulas (2004, p. 50), "Os bibliotecários estão cada vez mais conscientes de que têm um problema de imagem: não há dúvida de que a sociedade dos nossos dias atribui uma grande importância à imagem". Por isso, sabe da necessidade de mudar a imagem estereotipada que possui perante esta sociedade, tendo em vista o desconhecimento, em geral, sobre quem é e o que faz. Para Grogan (1995, p.13) "mesmo o usuário habitual de bibliotecas pouco sabe a respeito das tarefas que os bibliotecários executam, e os não-usuários inevitavelmente saberão menos".

Pode-se, portanto, justificar os estereótipos em torno dessa imagem, talvez, pelo fato de que uma parcela expressiva da população brasileira vive à margem dos direitos e deveres constituídos na sociedade; ou melhor, vive à margem do direito inalienável à informação. Se a preocupação da população não se voltar para o aspecto informacional, que valor terá para ela a biblioteca e o bibliotecário?

[...] a biblioteca também foi e continua sendo vista como dissociada dos interesses da maioria da sociedade; como um equipamento cultural que contribui para a perpetuação de uma estrutura em que o saber é ferramenta para ampliação das 
desigualdades; como uma instituição cujas ações reforçam e ampliam o fosso entre os que possuem e os que não possuem informação (ALMEIDA JúNIOR, 2004, p. 72).

Sendo assim, é exigida do bibliotecário uma postura dinâmica e próativa, que desperte na população em geral o interesse em freqüentar a biblioteca e, logo, usufruir da oferta de produtos e serviços, a fim de incluí-la nesta sociedade que se diz ser para todos.

Almeida Junior (2004, p. 91) traz para o contexto desta problemática a falta de conhecimento sobre a sua verdadeira função social,

[...] que não é apenas incentivar a leitura, mas trabalhar com a informação, levá-la àqueles que dela necessitam. Através dela, permitir que a população conheça seus direitos saiba como reivindicá-los, possua uma consciência social e política que possa transformar toda essa estrutura social.

Para alguns autores, o caráter predominantemente feminino da profissão integra o conjunto de variáveis que podem ofuscar o seu reconhecimento. Principalmente em uma sociedade onde a figura da mulher se confunde com vários preconceitos (MARCHIORI, 1996). Nessa direção, Almeida Junior (2000) diz que a Biblioteconomia sempre esteve ligada a atividades que funcionam como alimento do espírito - a leitura, o saber, a educação -, e estas atividades não se vinculavam ao conceito de produção em dada época da sociedade capitalista. Isto contribuiu para que a Biblioteconomia se tornasse predominantemente feminina, visto que as atividades de produção, mais valorizadas pelo sistema capitalista, eram designadas aos homens. De acordo com Souto (2005, p. 35), esta situação está mudando. "Felizmente, nos últimos anos, está havendo uma crescente procura do curso pelos homens. Acreditamos que isso se deve à abertura do mercado para os profissionais da informação $[\ldots] "$.

Dentre os estereótipos, situam-se aqueles que definem 0 bibliotecário como profissional apático, passivo, com pouca capacidade de articulação política e de organização com seus pares em entidades de classe. Sua imagem também é associada àquela pessoa mal humorada e antipática, que impõe normas e sanções aos usuários, se relacionando com eles de maneira autoritária em vez de carismática (SOUTO, 2005).

Quanto à apatia, pode-se, talvez, associá-la à falta de interesse pelas questões do cotidiano de sua atuação. Quem sabe, essa característica pessoal pode estar ligada ao fato do curso de Biblioteconomia não corresponder, às vezes, à primeira opção feita pelo aluno no concurso vestibular. Nesse caso, a garantia do diploma universitário (MARCHIORI, 1996) pode ser vista como passaporte às aspirações de ordem financeira do aluno egresso, com a perspectiva de ingressar no mercado de trabalho.

Arrisca-se dizer que o comportamento passivo pode estar ligado ao desinteresse pela capacitação e atualização contínuas. Essa passividade contraria sobremodo, a lógica que deve embasar a sua atuação, ou seja: 
Algumas características são fundamentais no profissional da informação, podendo ser nato ou não, como: criativo, investigativo, de senso crítico, empreendedor, proativo, dinâmico, político, entre outras. No caso de o profissional não possuí-las, será necessário desenvolvê-las durante a sua formação ou atualização, buscando uma melhor atuação profissional no mercado de trabalho (ABEBD, 1998 citado por VALENTIM, 2000, p. 140).

Uma questão polêmica e geradora de controvérsias apresentada na literatura da área se refere à denominação atribuída ao profissional egresso de cursos de Biblioteconomia. Para muitos, o termo bibliotecário remete a idéia do profissional que trabalha em bibliotecas tradicionais, onde o principal suporte informacional continua sendo o livro impresso. A palavra, bibliotecário, tem uma conotação muito forte que liga 0 profissional ao ambiente da biblioteca e não ao ambiente da informação (SOUTO, 2005). Existem autores que defendem a mudança do nome da profissão com veemência, em razão do rótulo que designa tanto a profissão quanto o profissional que nela atua.

Por que insistir no uso do termo bibliotecário, se a própria literatura da área o apresenta como não mais correspondendo à real atuação do profissional que atua em unidades de informação? Há sim uma conotação que acompanha a palavra bibliotecário e a remete para as esferas do ultrapassado, do retrógrado, do desnecessário. Acreditando-se que a profissão bibliotecária é útil socialmente e possui uma ação única, exclusiva e necessária para a sociedade, qualquer proposta de alteração do nome do profissional que a exerce é justificada (ALMEIDA JÚNIOR, 2000, p. 32),

De acordo com o autor citado, os nomes que contam com maior aceitação no meio acadêmico são os seguintes: Cientista da Informação/Conhecimento e Gestor da Informação/ Conhecimento, além de Profissional da Informação. Este termo ultimamente citado possui significado extensional, e vem sendo proposto para designar bibliotecários e todos os profissionais que têm a informação como objeto de trabalho.

Talvez, a dificuldade de aceitação ou consenso para a mudança de nome conte com o receio de que seja extinta a profissão. Porém, acreditase que essa mudança acarretaria, apenas, uma atualização necessária à colocação da profissão do bibliotecário em evidência na atual sociedade, que se rotula como sendo da informação e do conhecimento. Deve-se ressaltar que a simples mudança de nome, sem que haja mudança de atitude, é pouco para modificar o seu reconhecimento social, podendo até reforçar seus estereótipos.

Nessa perspectiva, Souza (2004) explica que a classe bibliotecária no Brasil tem buscado uma identidade profissional mediante a mudança 
de nome da sua profissão, ao passo que deveria buscar essa identidade nas ações sociais cumpridas por esses profissionais.

O nome profissional 'Bibliotecário' está em discussão e tudo indica que deve continuar em discussão pelo fato de que o problema de sua significação não está na substância das ações socialmente cumpridas pelos portadores desse papel. [...] 0 que parece estar acontecendo é uma tentativa de mudança de 'rótulos' e isso é o que o discurso liberal tem feito nos anos da década do século XX [...] (SOUZA, 2004, p. 104).

Os estereótipos construídos e perpetuados em torno da imagem do bibliotecário são vários, o que reforça o interesse das autoras em estudar o assunto. Em face dessas limitações, serão abordadas a seguir as possibilidades que se visualizam para o marketing profissional, a partir do endomarketing e do marketing pessoal.

\section{As interfaces do marketing profissional}

O nascimento do marketing se constitui em uma questão controvertida, pois não se sabe ao certo quando surgiu a primeira idéia relacionada a este conceito. Muitos estudiosos situam a sua origem nas relações de troca estabelecidas em épocas longínquas; outros consideram a obra clássica de Adam Smith, intitulada A Riqueza das Nações, publicada em 1776, como sendo o marco de sua origem; outros, ainda, atribuem à Revolução industrial do final do séc. XIII, na Inglaterra, a base de seu surgimento (SIMÕES, 1978). No entanto, segundo Peter Drucker (citado por AMARAL, 1998), seus primeiros instrumentos (pesquisa e análise de mercado) foram inventados no seio da cultura ocidental, em 1850, por Cyrus H. McCormick.

Mas, foi somente a partir das primeiras décadas do século $X X$ que 0 marketing começou a ganhar importância e aceitação no meio empresarial. Percorreu-se um longo caminho até que o seu foco evoluísse para o cliente, ou seja, para a satisfação de suas necessidades e desejos. McCarthy (1976) identifica três fases dessa evolução: 1) produção ou produto (até 1930); 2) vendas (entre 1930 e 1950) e, 3) marketing (após 1950).

Dentre as abordagens conceituais contemporâneas,

O marketing pode entender-se como uma atitude ou filosofia de gestão que tem em devida consideração a satisfação das necessidades e desejos do consumidor. Uma prática que consiste em detectar, reconhecendo ou antecipando as necessidades ou desejos do consumidor; a satisfação dessas necessidades ou desejos através da criação e oferta no mercado de um produto certo, no momento certo, no local certo e no preço certo, usando os meios de comunicação adequados. O ponto de partida do marketing são, portanto, as 
necessidades, os desejos, os motivos e as procuras específicas das pessoas (PINTO; BARRULAS, 2004, p. 1).

Nas concepções do marketing, encontra-se embutida a idéia de que o mesmo procura criar e manter de forma favorável a imagem do produto junto ao consumidor. O produto é entendido como qualquer coisa que se ofereça ao mercado para satisfazer uma necessidade ou desejo. Sendo assim, o bibliotecário pode ser entendido como produto pessoa, na medida em que busca satisfazer necessidades de informação de usuários, por meio de sua atuação (SANTOS, 2002).

A opção pelo uso do marketing, visando-se promover a visibilidade pública do bibliotecário, consiste em uma possibilidade sedutora, haja vista o entendimento sobre o fato de que suas idéias vêm sendo bastante difundidas e utilizadas em todos os contextos mercadológicos e sociais. De acordo com Amaral (2001, p. 19), "o marketing é hoje aplicado em todas as áreas. As técnicas mercadológicas podem estar relacionadas à adoção de qualquer produto ou serviço, ou até mesmo de uma idéia, programa ou causa social $[\ldots]^{\prime \prime}$.

A literatura concernente à área de marketing possui um conjunto de fontes bastante amplo e privilegiado em termos de conteúdo, oferecendo registros acerca de sua aplicação em diferentes contextos mercadológicos (COBRA; ZWANG (1987); KOTLER, F. (1998, 2003); PRINGLE; THOMPSON (2000). ${ }^{1}$ Contudo, levando-se em consideração o escopo temático deste artigo, procura-se abordar na seção seguinte o Endomarketing e o Marketing Pessoal e suas interfaces com o marketing profissional.

\subsection{Endomarketing}

A boa impressão causada pelo atendimento prestado ao usuário de um serviço pode contribuir para o reconhecimento e valorização de todos aqueles que tenham optado por seguir uma carreira. Como diz Jung (2000, p. 68), "[...] o endomarketing é muito mais uma questão de atitude, envolvendo ações simples que promovem o encantamento do cliente", exemplificadas aqui pelo bom atendimento. Para Bekin (1995, p. 2), antecede a isto o trabalho em equipe, com fortes tendências à cooperação e ao envolvimento total dos colaboradores com os valores e objetivos da empresa.

Pode-se dizer que tais idéias encontram-se apropriadas ao entendimento dos objetivos do endomarketing, isto é,

[...] impregnar o serviço com uma filosofia de marketing
garantindo a motivação dos funcionários para o

COBRA, M; ZWARG, F. A. Marketing de serviços: conceitos e estratégias. São Paulo: McGraw-Hill, 1987.

KOTLER, P. Administração de marketing: análise, planejamento, implementação e controle. 5. ed. São Paulo: Atlas, 1998.

Marketing de $A$ a Z: 80 conceitos que todo profissional precisa saber. 3. ed. Rio de Janeiro: Campus, 2003.

PRINGLE, H; THOMPSON, M. Marketing social: marketing para causas sociais e a construção de marcas. São Paulo: Makron Books, 2000. 
desenvolvimento de uma orientação voltada para o cliente e do interesse pelo serviço; e atrair e manter os bons funcionários na instituição, que assim funcionarão, também, como profissionais de marketing no seu relacionamento com os utilizadores (PINTO; BARRULAS, 2004, p. 4).

Nesse cenário que se idealiza, Amadeu (2001, p. 152) destaca que a imagem de uma pessoa é um dos bens mais valiosos, e ganha importância na medida em que influencia de maneira positiva a imagem profissional. "Quando a imagem pessoal é afetada dentro do ambiente corporativo, a imagem profissional pode sofrer alterações, o que pode ocasionar a violação da identidade e da imagem da pessoa".

Com base no exposto, acredita-se que o Endomarketing, levado à prática, pode dar a sua contribuição para mudar os estereótipos construídos em torno da imagem do bibliotecário, que então abandona a postura passiva, apática, o mau-humor, para se tornar um profissional dinâmico, comunicativo, prestativo, carismático e com a auto-estima elevada. Sendo assim, justificam-se os investimentos feitos à equipe de trabalho.

\subsection{Marketing pessoal}

Há outra possibilidade pinçada no conjunto de estratégias favoráveis à mudança de estereótipos. O bibliotecário deve construir e manter uma imagem positiva sobre si mesmo, perante as pessoas com as quais convive. Essa imagem precisa ser percebida e aceita, em especial pelos usuários atendidos por ele, pelas pessoas com quem trabalha, e pela instituição para a qual trabalha; assim estará fazendo seu marketing pessoal, ou seja, vendendo seu produto pessoa.

Fazendo uma comparação dos conceitos de marketing para o produto pessoa, pode-se dizer que toda estratégia que leve a imagem do profissional (produto, pessoa) até o consumidor final, o cliente, que no caso do produto pessoa é o patrão, amigos, colegas de trabalho, esposa, etc, é marketing pessoal (SANTOS, 2002, p.21).

O marketing pessoal trabalha com o interior das pessoas, ajudando no desenvolvimento de características e habilidades que sobressaiam entre as demais, e entre profissionais no mercado de trabalho. Nesse sentido, Torquato $(2002$, p. 218) ressalta a sua utilidade para "[...] preencher as necessidades do profissional nesses tempos de alta competitividade e crescentes exigências por qualidade"; enquanto Vaz (2000, p. 303), buscando estabelecer o entendimento sobre o que vem a ser marketing pessoal, faz considerações acerca de sua importância como estratégia de adaptação mercadológica. Para tanto, a pessoa deve possuir consciência plena sobre a importância social de suas atividades, "[...] para mostrar que desempenha função relevante aos grupos beneficiários de 
sua atuação, e que tem condições de desenvolvê-la à altura das expectativas e necessidades [desses grupos]" (VAZ, 2000, p. 303).

Já Amadeu (2001, p. 154) diz que a imagem profissional é algo equivalente à 'marca' que uma pessoa constrói sobre si mesma. Porém, reconhece que "Não é fácil para uma pessoa construir sua imagem, sua marca, pois isso é um processo na sua carreira profissional, na qual, passo a passo, essa construção vai atingindo um grau mais elevado".

Nessa direção, a autora formula uma espécie de estratégia estruturada envolvida no segredo de uma marca. Os ingredientes dessa fórmula, segundo ela, consistem na superação de pressões do cotidiano, no relacionamento honesto com os concorrentes, em saber se expor e se relacionar com o mercado, em utilizar estratégias no momento preciso, em acompanhar as tendências, e em atingir objetivos. Caminhando nesse sentido, a pessoa propiciará "[...] uma sólida construção de imagem pessoal, que poderá proporcionar uma excelente imagem profissional" (AMADEU, 2001, p. 155).

Diante da possibilidade do bibliotecário investir no endomarketing e no marketing pessoal, corrobora-se a emergência da construção de uma imagem profissional positiva, visando-se o reconhecimento e a valorização de sua carreira em diferentes contextos de sua atuação.

\subsection{Marketing profissional}

Pereira, Prado e Carioca (2003, p. 8, grifo nosso) apresentam contribuições de relevo ao entendimento do marketing profissional. Esses autores fizeram uma releitura de idéias sobre a filosofia, as atividades e as técnicas do marketing, para adequar a sua aplicação ao conceito de marketing profissional, tais como:

1) Uma filosofia: A idéia central é a de que a razão de ser de uma atividade profissional e dos esforços e uso do talento de um profissional é satisfazer necessidades, sendo efetivamente útil à sociedade e obtendo aceitação baseada nesta utilidade.

2) Um conjunto de atividades: Tal como ocorre nas organizações, as pesquisas de marketing são de excelente ajuda nas decisões que envolvem uma carreira. Portanto, é necessário incorporar à gestão de carreira os conceitos de desenvolvimento do produto: comunicação, vendas, distribuição e pós-venda.

Não que um profissional seja um produto, mas sim suas credenciais para o exercício de certa atividade: a qualidade de seu trabalho, seu talento, sua disposição. Quando ofertados, entram em um regime de mercado, exigindo-se assim a prática dos conceitos de desenvolvimento de produto supracitados.

3) Um conjunto de técnicas: Os mesmos conhecimentos que se aplicam à promoção de uma empresa podem ser aplicados, 
com as devidas adaptações, à promoção de um profissional. Fazendo as coisas do modo certo, o profissional torna-se mais elegível e promovível.

Enquanto que o endomarketing volta-se à promoção de valores da empresa junto ao público interno (BEKIN, 1995) e o marketing pessoal à ampliação no campo de contatos (RIZZO, 1998 citado por AMADEU, 2001), o marketing profissional foca a sua atenção no profissional como um todo e nos seus projetos (XAVIER, 2000 citado por PEREIRA; PRADO; CARIOCA; 2003).

Contudo, salienta-se que nesses três contextos do marketing as ações têm como foco maior o cliente. De acordo com esses autores, no primeiro caso constata-se que essa promoção de valores deve cumprir a finalidade de servir ao cliente; no segundo caso, o que está em jogo é a criação de oportunidades visando-se vender o produto pessoa; e no caso do marketing profissional, este deve cumprir a finalidade de promover a relação entre um profissional e sua clientela.

De acordo com o que afirma Torquato (2002, p. 219),

Todas as pessoas que agem com mentalidade de marketing são bem-sucedidas. O desafio que se coloca, preliminarmente, é o de pensar de maneira mercadológica. O treino cotidiano faz parte da estratégia de incorporar o marketing às rotinas profissionais. Portanto, o primeiro passo é acreditar que um bom planejamento de marketing pessoal favorece 0 crescimento profissional.

Em face do que foi evidenciado, pode-se considerar o marketing profissional, o endomarketing e o marketing pessoal como sendo recursos estratégicos para que o bibliotecário alcance reconhecimento profissional, em razão de estereótipos construídos. Ao se sentir útil e motivado, sentirse-á realizado e, portanto, mais entusiasmado com a sua carreira, disposto a aceitar o desafio de ser criativo, inovador e dinâmico, para se consolidar como um profissional indispensável para a sociedade.

Em razão do exposto, o próximo assunto a ser tratado consiste em descrever ações voltadas para a aplicação do marketing na promoção da imagem do bibliotecário.

\section{0 bibliotecário, sua imagem e o marketing}

A partir de uma compilação de idéias selecionadas de livros e trabalhos sobre o tema, Pinheiro, Sales Neto e Barbosa (2005) resumem, em tópicos, o que foi considerado essencial sobre marketing pessoal. Serão abordados a seguir, os tópicos de maior relevância sob a ótica das autoras deste artigo.

a) Convívio social fora do ambiente de trabalho: o profissional deve utilizar o marketing pessoal para promover sua imagem em qualquer atividade social de que participe e nos seus diversos relacionamentos (família, amigos, igreja, etc.) 
b) Participação em eventos e publicação de artigos e livros: é importante que o profissional participe de congressos, seminários e palestras, não apenas como ouvinte, mas também expondo suas idéias por meio de debates e apresentação de trabalhos. Para ganhar visibilidade e credibilidade, recomenda-se, ainda, a publicação de artigos em revistas especializadas, jornais e livros.

c) Habilidade em lidar com outras pessoas: considera-se estratégia fundamental para o marketing pessoal a capacidade de desenvolver bons relacionamentos. Para isso, é necessário que o profissional demonstre: humildade para pedir conselhos e tirar dúvidas, empatia e bom-humor, cordialidade e compreensão, procurar ajudar na resolução de problemas, saber ouvir atentamente e mostrar interesse no que está sendo dito, se expressar de maneira não agressiva e autoritária, entre outras atitudes.

d) Aparência física e postura: são relevantes para causar boa impressão. É essencial investir no visual, usar roupas adequadas, zelar pela higiene pessoal e hábitos saudáveis, manter uma postura correta e ter uma boa dicção.

Segundo Santos (2002, p. 43), "Os profissionais que exploram a 'aparência' de maneira correta, promovem uma valorização da imagem profissional e consequentemente ocorre um registro positivo do profissional na mente do consumidor".

a) Conduta ética: o caráter e a conduta ética do profissional são tão importantes quanto suas habilidades e competências profissionais. A discrição, a honestidade e o equilíbrio emocional são qualidades muito valorizadas pelas instituições. Assim, a conduta e a ética são ações de marketing pessoal utilizadas para formar um profissional de sucesso.

b) Aprimoramento educacional: disto depende o crescimento profissional e a sua sobrevivência no mercado de trabalho. È essencial freqüentar cursos lato-sensu e strictu-sensu, dominar outros idiomas e acompanhar inovações tecnológicas, para alcançar uma carreira bem sucedida.

c) Planejamento de carreira: consiste em uma das principais características do marketing, fazendo-se necessário estabelecer metas e objetivos a curto, médio e longo prazo, que norteiem as atividades profissionais, a fim de garantir sucesso na carreira.

Torquato (2002) elenca 30 conceitos-chave que podem contribuir para expandir condições profissionais e qualidades pessoais. Reforçando os tópicos já citados, acrescenta o auto-conhecimento, a criatividade, o bom senso, a inovação, dentre outros, como possibilidades de crescimento profissional.

Tanto quanto o marketing pessoal, outras ações que visem à promoção, por meio da divulgação da profissão do bibliotecário, são consideradas importantes, sejam em nível individual, institucional, dos órgãos de classe, sejam no âmbito dos cursos de graduação e pósgraduação na área.

Guimarães (2004) se queixa do distanciamento existente entre dois mundos na Biblioteconomia: o mundo acadêmico (representado pelas instituições de nível superior) e o mundo dos órgãos ligados à atuação 
profissional (conselhos, associações, sindicatos, dentre outros). O autor propõe uma relação de cooperação entre esses mundos, mediante diálogos que propiciem a divulgação profissional e promovam uma visibilidade pública positiva da profissão $e$, consequentemente, do bibliotecário. Assim, ele se pronuncia:

O diálogo emerge, pois, não mais como perspectiva, mas como efetiva necessidade para a visibilidade - seja científica, seja social - da área como um todo e, por decorrência, para sua própria sobrevivência. Nesse contexto, uma perspectiva específica de diálogo, por meio de uma atividade mutuamente enriquecedora a ambos os contextos, consiste na divulgação profissional, que pode ser encarada como processo informativo, de cunho social, acerca de uma dimensão profissional (GUIMARÃES, 2004, p. 91).

O autor aponta quatro razões que justificam uma ação divulgadora da profissão, quais sejam: $1^{a}$ - as constantes mudanças ocorridas na sociedade estão valorizando cada vez mais a informação e os profissionais que com ela trabalham; $2^{a}$ - a expansão do mercado de trabalho para outros contextos além dos tradicionais, ampliando os horizontes profissionais; $3^{a}$ - a integração das escolas de Biblioteconomia, aproximando e consolidando as áreas de informação (Arquivologia, Biblioteconomia e Museologia); $4^{a}$ - uma maior demanda pelos cursos de Biblioteconomia no país. De acordo com a ampla divulgação coberta pela mídia, esta é uma área em expansão e tem se despontado no ranking das profissões do futuro.

Considera-se a promoção como sendo um dos meios mais eficazes para se atingir a divulgação, ao se lançar mão de uma variedade de técnicas, táticas e meios utilizados para fins específicos. Apesar de ser a atividade mais visível do marketing, não é única. Portanto, não deve limitar as ações de marketing, mas ser usada como possibilidade de divulgação.

A promoção pode realizar-se de diferentes maneiras. Podem ser consideradas como atividades de promoção ou promocionais as diversas e variadas possibilidades, formas ou técnicas mercadológicas para realizar a promoção. Cada autor interpreta a promoção a seu modo, e, de acordo com sua própria concepção, apresenta sua classificação para essas modalidades de promoção, elencando algumas ou todas as seguintes atividades ou técnicas promocionais: relações públicas, merchandising, propaganda, publicidade, promoção de vendas, venda pessoal, incentivos e atmosfera (AMARAL, 2001, p.28).

Amaral (2001), baseada em autores conceituados das áreas de Administração e Marketing, cita vários recursos promocionais como, por exemplo: amostras, cartazes, cinema, cupons, displays, embalagens, jornais, lista de correspondência, listas telefônicas, rádio e televisão, 
revistas, selos, vale-brindes e telefone. Apresenta, ainda, técnicas, ferramentas ou mecanismos promocionais, tais como: concursos, sorteios e jogos, contato pessoal, correspondência direta, espetáculos e exposições, mala direta, atuação porta a porta, prêmios e telemarketing. Tudo isso corrobora o desejo enunciado por Eggert e Martins (1996, p. 40), posto que:

A produção de um meio que venha divulgar aspectos relacionados ao profissional bibliotecário, e a conscientizar a população sobre eles, vem ao encontro da necessidade de mostrar a diferentes segmentos, as possibilidades de atuação deste profissional no mercado.

Quanto a isso, Guimarães (2004) concorda. Inclusive, segundo ele, a divulgação profissional deve ser destinada a três categorias principais de cidadãos: o cidadão-usuário, o cidadão-futuro-profissional e o cidadãoempregador.

No entanto, para que a divulgação profissional possa ser desenvolvida em moldes sistemáticos e comprometidos com o desenvolvimento da profissão e do profissional, é fundamental que a mesma seja efetivamente inserida no contexto pedagógico, de modo a que o tema esteja presente no âmbito curricular, nos cursos de biblioteconomia (GUIMARÃES, 2004, p. 95).

Tal queixa parece refletir inquietações por parte de outros pesquisadores da área, pois, de acordo com Eggert e Martins (1996, p. 46), "Os cursos de biblioteconomia atuam no sentido de mostrar ao acadêmico que assuma uma postura dinâmica frente à divulgação da biblioteca, inove o marketing, porém não atentam para uma divulgação do profissional".

Nas palavras de Guimarães (2004), a divulgação transcende a promoção, justamente pela possibilidade de utilizá-la como um fazer pedagógico comprometido com a realidade social. Nessa direção, destaca três objetivos a serem alcançados:

a) vencer os estigmas da imagem da profissão;

b) informar a comunidade sobre um conjunto de serviços - e um profissional especializado - a sua disposição;

c) informar aos cidadãos as perspectivas reais de uma carreira promissora e em franca ascensão.

Em conformidade com o que foi assinalado por Eggert e Martins (1996) e Guimarães (2004), as ações voltadas para a promoção da biblioteca, mediante a oferta de produtos e serviços, parecem estar mais consolidadas no meio biblioteconômico, em relação à divulgação profissional. Que esta divulgação necessite ser incorporada com maior veemência no rol das ações voltadas à valorização do bibliotecário, há de se concordar. 
Por outro lado, a par da projeção de uma melhor imagem da biblioteca no seio da comunidade decorrerá também, consequentemente, uma projeção de imagem muito favorável dos próprios profissionais, encarados cada vez mais como gestores de informação com um importante papel social a desempenhar, ou seja, trata-se aqui do reconhecimento do valor dos profissionais bibliotecários como agentes de responsabilidade social que, com a sua atividade, contribuem para o acesso à informação e, assim, para o desenvolvimento das comunidades (PINTO; BARRULAS, 2004, p. 5, tradução livre).

Desde há algum tempo, Amaral (1998) vem insistindo neste assunto: orientação para o marketing em unidades de informação. Além de concordar com o fato de que a adoção do marketing valoriza o profissional e melhora a sua imagem, ele também torna a comunicação entre biblioteca e usuário mais fluida, facilitando as trocas, superando barreiras, de modo a melhor satisfazer necessidades de informação desses usuários.

Em face dessa vocação atribuída ao marketing, as práticas de gestão em bibliotecas devem ser orientadas pela sua filosofia, pelas suas atividades e pelas suas técnicas, visando-se mover a construção de concepções sociais sobre a profissão do bibliotecário para uma realidade além do que a dos estereótipos construídos.

\section{Considerações finais}

As indagações feitas acerca das ações ligadas ao marketing, que podem promover uma melhor imagem do bibliotecário, colocaram o desafio de se ressaltar interfaces do marketing profissional com 0 endomarketing e o marketing pessoal.

Mediante leituras necessárias à formulação de respostas ao problema de pesquisa e ao cumprimento do objetivo principal, pôde-se usufruir oportunidades de reflexão ao longo do desenvolvimento do tema. Nesse percurso, as idéias de McCarthy (1976) sobre as três fases de evolução do marketing, reproduzidas na seção 4, permitiram que se inferisse sobre a possibilidade de a prática bibliotecária ter sido desde sempre impregnada, de certa forma, pelas idéias do marketing. Mesmo que não houvesse essa intencionalidade, pode-se dizer que: a fase de produção ou produto (até 1930), na Biblioteconomia, remete a fases em que a preocupação do bibliotecário centrava-se no produto acervo; a fase de vendas (entre 1930 e 1950), na Biblioteconomia, remete a fases em que o profissional se consolidava como disseminador da informação, porém, ainda muito centrado na organização do acervo; a fase do marketing, propriamente dito (após 1950), na Biblioteconomia, remete a fases em que se assiste à emergência de transposição paradigmática, centrada no acervo, evoluindo para a informação. Nesta última fase, o usuário passa a ser o foco principal das unidades de informação. 0 
bibliotecário busca conhecê-lo, antecipando-se às suas necessidades e demandas.

Tais tendências parecem corroborar, hoje, a aplicabilidade do marketing nas ações da biblioteca e, mais recentemente, nas ações do bibliotecário como produto pessoa, de modo a promover a sua imagem estereotipada por meio do marketing profissional. Isto pode levar a concepções mais avançadas sobre a imagem social do bibliotecário, conhecedor, aliás, das próprias limitações nesse sentido.

Embora o endomarketing, o marketing pessoal e o marketing profissional estejam focados em ações distintas, fica evidenciada nos três contextos a preocupação com o foco no cliente. Dessa maneira, entendese que as estratégias utilizadas pelo profissional com o objetivo de promover a si e a sua profissão interessam ao marketing profissional.

Considera-se pouco provável que o reconhecimento e a valorização do bibliotecário se dêem somente pelas ações isoladas. Por isso, entendese ser importantíssima a integração entre o mundo acadêmico (representado pelas instituições de nível superior) e o mundo dos órgãos ligados à atuação profissional (conselhos, associações, sindicatos, dentre outros), em projetos que visem à divulgação da profissão, segundo assinalado por Guimarães (2004).

Em síntese, para que os profissionais da área de Biblioteconomia conquistem o desejável reconhecimento e valorização, terão que se encorajar na construção e na participação de projetos dimensionados pela grandeza de vencer o notável compromisso de divulgar a sua profissão, em prol da sua visibilidade pública.

\section{Referências}

ABEBD, 1998 citado por VALENTIM, M. L. P. (Org.) Profissionais da informação: formação, perfil e atuação profissional. São Paulo: Polis, 2000. 156 p.

ALMEIDA JÚNIOR, O. F. Profissional da informação: entre o espírito e a produção. In: VALENTIM, M. L. P. (Org.). O profissional da informação: formação, perfil e atuação profissional. São Paulo: Polis, 2000. p. 31-51.

- Profissional bibliotecário: um pacto com o excludente. In: BAPTISTA, S. G; MUELLER, S. P. M. (Org.). Profissional da Informação: o espaço de trabalho. Brasília: Thesaurus, 2004. p. 70-86.

AMADEU, D. A. F. Sobrenome empresarial: o brasão dos nossos tempos. Caderno de Administração PUC-SP, n.1, p. 147-166, 2001.

AMARAL, S. A. Marketing: abordagem em unidades de informação. Brasília: Thesaurus, 1998.

Jurídica, 2001.

Promoção: o marketing visível da informação. Brasília: Ed.

BEKIN, S. F. Conversando sobre endomarketing. São Paulo: Makron Books, 1995. 
CAMPELLO, B. S., CENDON, B. V, KREMER, J. M. Fontes de informação para pesquisadores e profissionais. Belo Horizonte: Ed. UFMG, 2000.

COBRA, M.; ZWARG, F. A. Marketing de serviços: conceitos e estratégias. São Paulo: McGraw-Hill, 1987.

EGGERT, G.; MARTINS, M. E. G. Bibliotecário: quem é? O que faz? Revista ACB: Biblioteconomia em Santa Catarina, Florianópolis, v.1, n.1, p. 45-48, 1996.

GIL, A. C. Como elaborar projetos de pesquisa. 3. ed. São Paulo: Atlas, 1995.

GROGAN, D. A prática do serviço de referência. Brasília: Briquet de Lemos Livros, 1995.

GUIMARÃES, J. A. C. A divulgação profissional como perspectiva de diálogo entre a atividade acadêmica e a prática profissional: reflexões sobre uma prática pedagógica na área de fundamentos de biblioteconomia e ciência da informação. In: RODRIGUES, M. E. F.; CAMPELLO, B. S. (Org.). A (re)significação do processo de ensino: aprendizagem em Biblioteconomia e Ciência da Informação. Niterói: Intertexto, 2004. p. 8999.

JUNG, A. P. Endomarketing é questão de atitude. Marketing, São Paulo, n. 325, p.68-69, fev. 2000.

KOTLER, P. Administração de marketing: análise, planejamento, implementação e controle. São Paulo: Atlas, 1998.

- Marketing de $A$ a Z: 80 conceitos que todo profissional precisa saber. Rio de Janeiro: Campus, 2003.

KUPLICH, A. Endomarketing em unidades de informação biblioteconômicas. 2004. Monografia (Graduação em Biblioteconomia) Departamento Ciência da Informação, Universidade Federal do Espírito Santo, Vitória, 2004.

LAKATOS, E. M.; MARCONI, M. A. Metodologia do trabalho científico: procedimentos básicos, pesquisa bibliográfica, projeto e relatório, publicações e trabalhos científicos. São Paulo: Atlas, 1992.

MARCHIORI, P. Z. Bibliotecários, jornalistas e informáticos: a ocupação de posições relativas no campo de atividades de informação. Transinformação, Campinas, v. 8, n. 1, p. 89-111, jan./abr. 1996.

MC CARTHY, E. J. Marketing básico: uma visão gerencial. Rio de Janeiro: Zahar, 1976.

MILANESI, L. Biblioteca. São Paulo: Ed. Ateliê , 2002.

OLIVEIRA, M. Os paradigmas da Ciência da Informação. In: SIMPÓSIO BRASIL-SUL DE INFORMAÇÃO, 1996, Londrina. Anais... Londrina: UEL/Departamento de Biblioteconomia, 1996. 
PARENTE, A. O virtual e o hipertextual. Rio de Janeiro: Pazulin / Núcleo de Tecnologia da Imagem - ECO-UFRJ, 1999 citado por SILVA, T. E.; TOMAÉL, M. I. Fontes de informação na Internet: a literatura em evidência. In: TOMAÉL, M. I.; VALENTIM, M. L. P. (Orgs.). Avaliação de fontes de informação na Internet. Londrina: Eduel, 2004.

PEREIRA, A. P.; PRADO, E. V.; CARIOCA, J. M. Gestão da carreira: planejando para atingir objetivos. In: ENCONTRO DE GRADUANDOS DE ADMINISTRAÇÃO E CIÊNCIAS CONTÁBEIS, 2., São Paulo, 2003. Disponível em: <http://www.feob.br/novo/egracc2004/eventos\%2520anteriores/egracc\% 25202003/Trabalhos/011.pdf>. Acesso em: 19 jun. 2006.

DRUCKER, P. F. Administração: tarefas, responsabilidades, práticas. São Paulo: Pioneira, 1975. v.1 citado por AMARAL, S. A. Marketing: abordagem em unidades de informação. Brasília: Thesaurus, 1998.

PINHEIRO, A.; SALES NETO, F. L.; BARBOSA, M. A utilização do marketing pessoal pelos advogados de Salvador. 2005. 91f. Monografia (Especialização em Administração) - Núcleo de Pós-Graduação em Administração, Universidade Federal da Bahia, Salvador, 2005. Disponível em: <http://www.adm.ufba.br/CPA monografias/turma $0401 /$ utilizacao marketing pessoal advogados.pdf>. Acesso em: 27 jul. 2006.

PINTO, M. L.; BARRULAS, M. J. A disciplina de marketing e a prática do bibliotecário: estudo de caso em bibliotecas da RNBP. In: CONGRESSO NACIONAL DE BIBLIOTECÁRIOS, ARQUIVISTAS E DOCUMENTALISTAS, 8., 2004, Lisboa, Actas... Lisboa: APBAD, 2004.

PRINGLE, H; THOMPSON, M. Marketing social: marketing para causas sociais e a construção de marcas. São Paulo: Makron Books, 2000.

RIZZO, C. Marketing pessoal. São Paulo: Terra, 1998. citado por AMADEU, D. A. F. Sobrenome empresarial: o brasão dos nossos tempos. Caderno de Administração PUC-SP, n.1, p. 147-166, 2001.

SANTOS, L. Marketing pessoal e sucesso profissional. Campo Grande: UCDB, 2002.

SEVERINO, A. J. Metodologia do trabalho científico. 21. ed. São Paulo: Cortez, 2000.

SILVA, T. E.; TOMAÉL, M. I. Fontes de informação na Internet: a literatura em evidência. In: TOMAÉL, M. I.; VALENTIM, M. L. P. (Orgs.). Avaliação de fontes de informação na Internet. Londrina: Eduel, 2004.

SIMÕES, R. Iniciação ao marketing. 4. ed. São Paulo: Atlas, 1978.

SOUTO, L. F. Biblioteconomia em reflexão: cenários, práticas e perspectivas. In: SOUTO, L. F. (Org.). O profissional da informação em tempo de mudanças. Campinas: Ed. Alínea, 2005. p. 29-53.

SOUZA, F. C. O no me profissional "bibliotecário" no Brasil: o efeito das mudanças sociais e econômicas dos últimos anos do século XX. Encontros 
Bibli: Revista Eletrônica de Biblioteconomia e Ciência da Informação. Florianópolis, n.18, $2^{\circ}$ sem. 2004

TARGINO, M. G. Olhares e fragmentos: cotidiano da Biblioteconomia e Ciência da Informação. Teresina: EDUFPI, 2006.

TORQUATO, G. Tratado de comunicação organizacional e política. São Paulo: Pioneira, 2002.

VALENTIM, M. L. P. (Org.). O profissional da informação: formação, perfil e atuação profissional. São Paulo: Polis, 2000. 156 p.

VAZ, G. N. Marketing institucional: o mercado de idéias e imagens. 2.ed. São Paulo: Pioneira, 2000.

XAVIER, R. A. P. Você S.A.: como administrar sua carreira como se fosse um negócio. São Paulo: Ed. STS, 2000 citado por PEREIRA, A. P.; PRADO, E. V.; CARIOCA, J. M. Gestão da carreira: planejando para atingir objetivos. In: ENCONTRO DE GRADUANDOS DE ADMINISTRAÇÃO E CIÊNCIAS CONTÁBEIS, 2., São Paulo, 2003. Disponível em: <http://www.feob.br/novo/egracc2004/eventos\%2520anteriores/egra cc\%25202003/Trabalhos/011.pdf >.Acesso em: 19 jun. 2006. 